\title{
Porous PCL/Chitosan and nHA/PCL/Chitosan Scaffolds for Tissue Engineering Applications: Fabrication and Evaluation
}

\author{
Rashid Mad Jin, ${ }^{1}$ Naznin Sultana, ${ }^{1,2}$ Sayang Baba, ${ }^{1}$ \\ Salehhuddin Hamdan, ${ }^{1}$ and Ahmad Fauzi Ismail ${ }^{2}$ \\ ${ }^{1}$ Faculty of Biosciences and Medical Engineering (FBME), Universiti Teknologi Malaysia UTM, 81310 Johor Bahru, Johor, Malaysia \\ ${ }^{2}$ Advanced Membrane Technology Center (AMTEC), Universiti Teknologi Malaysia UTM, 81310 Johor Bahru, Johor, Malaysia \\ Correspondence should be addressed to Naznin Sultana; naznin@biomedical.utm.my
}

Received 1 September 2014; Accepted 18 October 2014

Academic Editor: Qi Xing

Copyright (C) 2015 Rashid Mad Jin et al. This is an open access article distributed under the Creative Commons Attribution License, which permits unrestricted use, distribution, and reproduction in any medium, provided the original work is properly cited.

\begin{abstract}
Two semicrystalline polymers were blended to fabricate porous scaffolds for tissue engineering applications. Scaffolds containing polycaprolactone (PCL)/chitosan and nanohydroxyapatite (nHA) incorporated nHA/PCL/chitosan were produced using the freeze-drying technique. A model drug, tetracycline hydrochloride (tetracycline HCL), was incorporated into the scaffolds. The scaffolds were characterized using a scanning electron microscope (SEM), EDX, and water contact angle. The antibacterial properties of the $\mathrm{nHA} / \mathrm{PCL} / \mathrm{chitosan} /$ tetracycline HCL scaffold were tested and the scaffolds showed positive results on grampositive and gram-negative bacteria. The cell biocompatibility using human skin fibroblast cells (HSF 1184) was examined. The scaffold materials were found to be nontoxic to human skin fibroblast cells (HSF 1184) and showed positive proliferation activities. The nHA/PCL/chitosan/tetracycline HCL scaffold has potential for controlling implant-associated bacterial infections during operative procedures and can potentially be used as a scaffold for tissue engineering applications.
\end{abstract}

\section{Introduction}

Scaffold-based tissue engineering involves the combination of an artificial extracellular matrix (ECM) and three-dimensional scaffolds containing living cells and/or regulating biomolecules, such as growth factors. The scaffold acts as the central component that mimics ECM, whereas the cells and growth factors interact with each other to regenerate targeted tissues [1]. In bone tissue engineering, the scaffold needs to have several characteristics. It should be an osteoconductive 3D-template, consisting of interconnected pores, and act as a structural support for newly formed bone [2]. Interconnected pores play an important role in supporting cell penetration, new tissue ingrowth, nutrient diffusion, and neovascularization.

Polycaprolactone (PCL) is a biodegradable and biocompatible polymer with a slow degradation rate. PCL can be blended with other polymers to improve stress crack resistance, hydrophilicity, degradation rate, and cell adhesion. Different studies have shown PCL blended with different polymers, such as cellulose propionate and cellulose acetate butyrate to manipulate the drug release rate from microcapsules [3].

Chitosan has been extensively used in the field of tissue engineering because it is biodegradable, biocompatible, and nontoxic; moreover, it has antibacterial properties. Chitosan's main functional groups are hydroxyls, acetamides, and amines that are very reactive [4]. Studies regarding PCL/ chitosan composite scaffolds are still dormant. It was reported that chitosan enhanced wettability and permeability, accelerated PCL hydrolytic degradation, and improved PCL cell recognition sites [5]. For bone tissue engineering, the use of tetracycline is still not well studied. Recent studies showed positive results for the treatment of osteoporotic bone loss using tetracycline [6-9].

Nanohydroxyapatite $\left(\mathrm{Ca}_{10}\left(\mathrm{PO}_{4}\right)_{6}(\mathrm{OH})_{2}\right)$ is one of the bioceramics that have similar properties of mineral components of natural bone and often can be used as synthetic bone graft, as drug carrier, and also as metal prosthesis coating [10]. In fact, addition of nHA to the scaffolds will improve the in vitro or in vivo performance of the material as the bioactive compounds like nHA are able to form direct 
bonding to the surrounding tissues [10]. PCL/chitosan composite scaffolds were prepared using freeze-drying technique [11]. Similar to other methods such as particle leaching [12], wet-spinning [13], and selective laser sintering [14], freezedrying technique produces scaffolds with high porosity and well-connected pores.

In this research, PCL/chitosan composite scaffolds were synthesized for bone regeneration applications. Three types of scaffolds, namely, PCL/chitosan, nHA incorporated nHA/ $\mathrm{PCL} /$ chitosan, and tetracycline $\mathrm{HCL}$ incorporated $\mathrm{nHA} /$ $\mathrm{PCL} /$ chitosan, were fabricated and their properties were evaluated. Antibacterial properties of the scaffolds were investigated. In vitro biological evaluations of the scaffolds were conducted using human skin fibroblast (HSF 1184) cells for cytotoxicity, cell attachment, and cell proliferation.

\section{Materials and Methods}

2.1. Materials. Chitosan (medium molecular weight, degree of deacetylation $=90 \%$ ) in $2 \mathrm{wt} \%$ acetic acid solution was prepared using glacial acetic acid in ultrapure Milli-Q water. Poly- $\varepsilon$-caprolactone (PCL), molecular mass $\left(M_{n}\right) 70,000-$ 80,000 , Dulbecco's modified eagle medium (DMEM), MTT [3-4,5-dimethylthiazol-2yl \{-2, 5 diphenyl-2H-tetrazoliumbromide\}], and fetal bovine serum (FBS) were purchased from Sigma-Aldrich, USA. $\mathrm{NaOH}$ and other reagents were all of analytical grade.

\subsection{Methods}

2.2.1. Production of $n H A$. The $\mathrm{nHA}$ was prepared in house using the nanoemulsion technique, where $4.045 \mathrm{~g}$ of $\left(\mathrm{NH}_{4}\right)_{2} \mathrm{HPO}_{4}$ was dissolved into $700 \mathrm{~mL}$ of ultrapure deionized water in a beaker [15]. Then, $1 \mathrm{M} \mathrm{NaOH}$ was added to the solution until the $\mathrm{pH}$ of the solution was 11 . The change in $\mathrm{pH}$ was measured using a $\mathrm{pH}$ meter. Ultrapure deionized water was then added for a final solution volume of $1 \mathrm{~L}$. Meanwhile, $11.973 \mathrm{~g}$ of $\mathrm{Ca}\left(\mathrm{NO}_{3}\right)_{2} \cdot 4 \mathrm{H}_{2} \mathrm{O}$ was dissolved in $100 \mathrm{~mL}$ of acetone in a Scotch bottle to form the oil phase. The aqueous phase was transferred into a $2 \mathrm{~L}$ beaker and mixed with the oil phase under stirring at $800 \mathrm{rpm}$ for $0.5 \mathrm{~min}$ at room temperature. The mixed solution was then filtered using filter paper (gravitational filtration), and the precipitation was washed several times to remove any organic solvent. The precipitation was transferred into several small containers and was refrigerated for one day. The frozen nanoemulsion was freeze-dried for three days to obtain nHA powder.

2.2.2. Preparation of PCL/Chitosan Composite Scaffolds. Three composite scaffold samples were prepared: PCL/ chitosan, nHA/PCL/chitosan, and nHA/PCL/chitosan/tetracycline HCL scaffolds. To prepare the $5 \mathrm{wt} \%$ PCL solution, PCL (70-90 kD, sigma Aldrich) was dissolved in glacial acetic acid and kept stirring for $30 \mathrm{~min}$ at room temperature. Then, $2 \mathrm{wt} \%$ chitosan powder $(250 \mathrm{kD}, 80$-mesh chitosan, $85 \%$ deacetylated) was added to the solution, and the blends were kept stirring for hours until a clear viscous solution was obtained. nHA (10 wt \%) was added and homogenized using a homogenizer, and approximately $0.04 \mathrm{~g}$ of tetracycline HCL was added to the solution and stirred until a viscous solution was obtained. The solution was then transferred into a mold and frozen overnight; all of the samples were lyophilized in a freeze dryer until dried. Then, the scaffolds were cut into $1.2 \mathrm{~cm}$ diameter and 0.2 height samples. The scaffolds were washed with $0.2 \mathrm{M} \mathrm{NaOH}$ solution and rinsed with distilled water several times to remove any residual acetic acid.

2.2.3. Characterization of Composite Scaffolds. The surface morphologies of all of the scaffolds were examined by scanning electron microscopy (SEM, Table Top TM3000) and FESEM (HITACHI SU8020). Water contact angles were measured using a contact angle instrument (VCA-Optima, AST Inc., USA). A drop of deionized water was placed onto the surface of the scaffolds to determine the wettability of each sample.

2.2.4. Swelling Studies. All of the dry scaffolds were weighed, noted as $W_{o}$. Then, the scaffolds were immersed in phosphate buffered saline (PBS) at $\mathrm{pH} 7.4$ at $37^{\circ} \mathrm{C}$ for 24 hours. After $24 \mathrm{~h}$, the scaffolds were removed and wiped with filter paper to remove any adsorbed water. The wet weights of the scaffolds were taken, noted as $W_{w}$. The ratio of swelling was determined using the following formula: swelling ratio $=W_{w}-$ $W_{o} / W_{o}$.

2.2.5. Cytotoxicity. Human skin fibroblasts (HSF 1184) were used in this experiment for the MTT assay of the scaffolds. HSF cell optimizations were carried out by seeding various concentrations of cells onto 24 -well plates for three days. The isolated and passaged cells were trypsinized, pelleted, and resuspended in a known amount of DMEM media. The cells were counted and diluted to a concentration based on optimization for the cells $\left(2 \times 10^{5} / \mathrm{cm}^{2}\right)$ and seeded onto the 24 well plate for $24 \mathrm{~h}$. The scaffolds were weighed and immersed into DMEM for $24 \mathrm{~h}$. The supernatants were taken out and added to the cell-containing wells at different volumes $(0,10$, $30,50$, and $100 \mu \mathrm{L})$. Triton X-100 (0.1\%) was added to the wells and incubated for three days. Then, the media was removed and $500 \mu \mathrm{L}$ of MTT solution $(0.05 \%)$ was added to the wells. Cells were incubated for $4 \mathrm{~h}$, and $0.1 \mathrm{M} \mathrm{HCl}$-isopropanol buffer was used for dissolving the formazan crystals. The optical densities were examined using a spectrophotometer (ELISA microplate reader, Epoch, Biotek) at $570 \mathrm{~nm}$. The results were compared to controls and analyzed statistically.

2.2.6. Proliferation Activities. Proliferation activities of human skin fibroblasts (HSF 1184) were monitored in this experiment on the surfaces of the scaffolds. Cells $\left(2 \times 10^{5} /\right.$ $\mathrm{cm}^{2}$ ) were seeded onto the scaffolds, and $1 \mathrm{~mL}$ DMEM was added. All samples were prepared in three replicates for three days, and the cytotoxicity activities were followed. Readings were taken on day 1 , day 2 , and day 3 to form a graph.

2.2.7. Antibacterial Activity. The antibacterial activities of composite scaffolds were investigated by a zone inhibition method. The scaffolds were cut into pieces that were $2 \mathrm{~cm}$ 

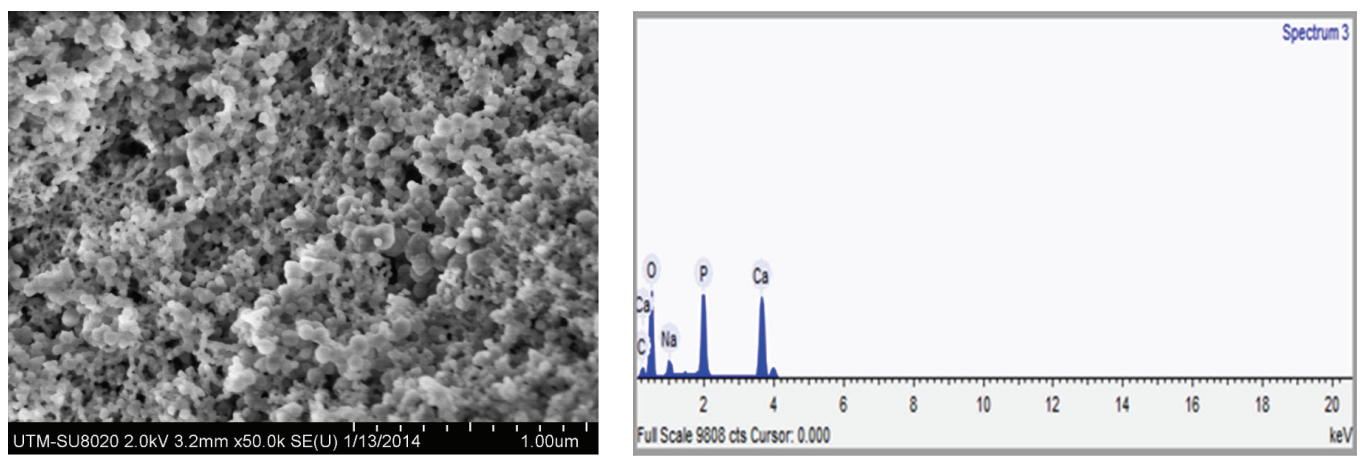

FIGURE 1: FESEM image and EDX of the HA nanoparticles.

in height and 1.6 in diameter, in triplicate. Gram-negative and gram-positive bacteria were used as the model microorganisms. Using the spread plate method, NA plates were inoculated with $1 \mathrm{~mL}$ of bacterial suspension containing approximately $10^{5} \mathrm{cfu} / \mathrm{mL}$ of each bacterium. The scaffolds were gently placed on the inoculated plates and were incubated at $37^{\circ} \mathrm{C}$ for $24 \mathrm{~h}$. Zones of inhibition were determined by measuring the clear area formed surrounding each scaffold.

2.2.8. Statistical Analysis. Data analysis was carried out using Student's two-tailed $t$-test. A value of $P<0.05$ was considered statistically significant in each $t$-test case.

\section{Results and Discussion}

3.1. Characterization of Hydroxyapatite. nHA has been widely used in implantable materials in medicine because it has good biocompatibility, and for most, its high osteoconductive property is very suitable for regeneration of bone tissues. In this research, nHA, as shown in Figure 1, has been synthesized using a nanoemulsion freeze-drying technique, showing amorphous nanoparticles with average sizes of 40$80 \mathrm{~nm}$, and based on EDX, its Ca-P ratio is 1.53. The range of $\mathrm{Ca} / \mathrm{P}$ ratio of $\mathrm{nHA}$ is within $1.50-1.67$ which is suitable to promote bone regeneration [15]. The FESEM images of nHA are shown in Figure 1.

3.2. Characterization of the Scaffolds. All of the scaffolds were prepared using the frozen solvent extraction method. Blending PCL and chitosan in a single phase using acetic acid solution without complex chemical modifications produced scaffolds with irregular pores and a high pore distribution. Figure 2 shows SEM images of the scaffolds. All of the scaffolds show highly interconnected porous structures. The average pore sizes of the PCL/chitosan, nHA/PCL/Chitosan, and nHA/PCL/chitosan/tetracycline HCL scaffolds were $59.47 \pm$ $20.8,12.39 \pm 5.2$, and $34.55 \pm 13.8 \mu \mathrm{m}$, respectively. These structures are very vital to tissue engineering applications as they allow the harboring of cells, cell penetration and migration, tissue ingrowth, vascularization, and nutrient supply within the targeted area [16]. Other aspects should also be considered because the images showed the roughness of the walls of the scaffolds, which will help cell adhesion and spreading.

Comparing pure chitosan scaffold to $\mathrm{PCL} /$ chitosan scaffold, the surface morphology of the pure chitosan showed closed pores, whereas the blended chitosan showed elongated and irregular pores. However, both of them showed very good connectivity between the pores, which is advantageous for tissue ingrowth. Another reason for these phenomena is that the blend of PCL and chitosan using this simple method did not involve any chemical modifications of the polymer in advance.

3.3. Contact Angle and Swelling Studies. The results from the contact angle measurements of the three scaffolds, as shown in Table 1 , showed angles within the range of $75.0^{\circ}$ to $65.0^{\circ}$, which indicated that the surfaces of the scaffolds were hydrophilic. The results also showed that the wettability of the composite scaffold of nHA/PCL/CHT increased. All of the scaffolds were hydrophilic because of the amino groups present on the surfaces of the scaffolds.

From Figure 3, showing the results of the swelling studies, the $\mathrm{nHA} / \mathrm{PCL} / \mathrm{chitosan}$ scaffold retained the most water, followed by the nHA/PCL/chitosan/tetracycline HCL and the $\mathrm{PCL} /$ chitosan scaffolds after a 24-hour incubation period in

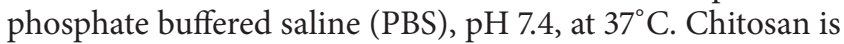
more hydrophilic than PCL, which is hydrophobic, whereas blending of these two polymers changes the wettability of the composite scaffold. The mechanical properties of the scaffolds are related to the swelling of the scaffolds. The swelling effect will loosen the scaffold from its implanted site and generate unnecessary stress on surrounding tissues. $\mathrm{PCL} /$ chitosan scaffolds showed the lowest swelling compared to the other scaffolds, indicating that it had good mechanical strength to support bone tissue in growth. These results also proved that HA improved the rate of water absorption into the scaffolds.

Blending has increased the ability of PCL to absorb water, while retaining its unique characteristics, such as low degradation rate and high mechanical strength [5]. The combination of both polymers produced scaffolds that have high porosity, are hydrophilic, have high mechanical strength, and have longer degradation rates [5]. 


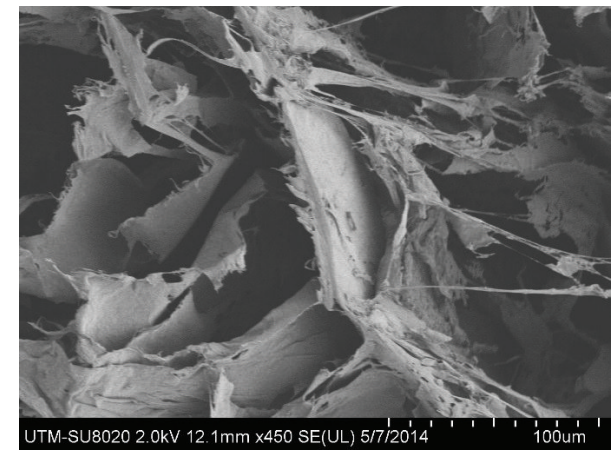

(a)

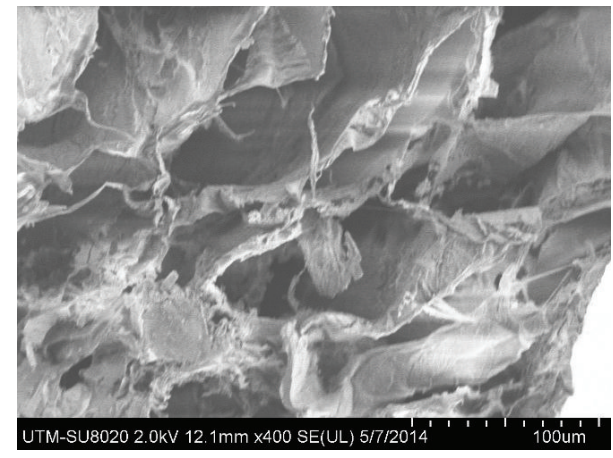

(b)

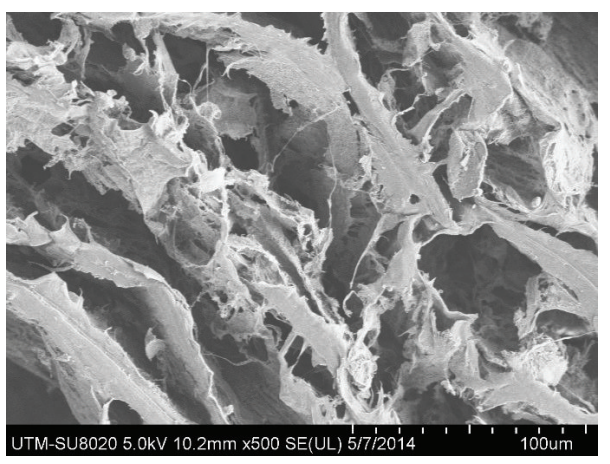

(c)

FIGURE 2: SEM images of (a) PCL/chitosan; (b) nHA/PCL/chitosan; (c) nHA/PCL/chitosan/tetracycline HCL scaffolds.

TABLE 1: Contact angle measurements of the different types of scaffolds.

\begin{tabular}{llll}
\hline Scaffold & PCL/CHT & nHA/PCL/CHT & nHA/PCL/CHT/TTC HCl \\
Contact angle & $70.925^{\circ} \pm 2.99$ &
\end{tabular}

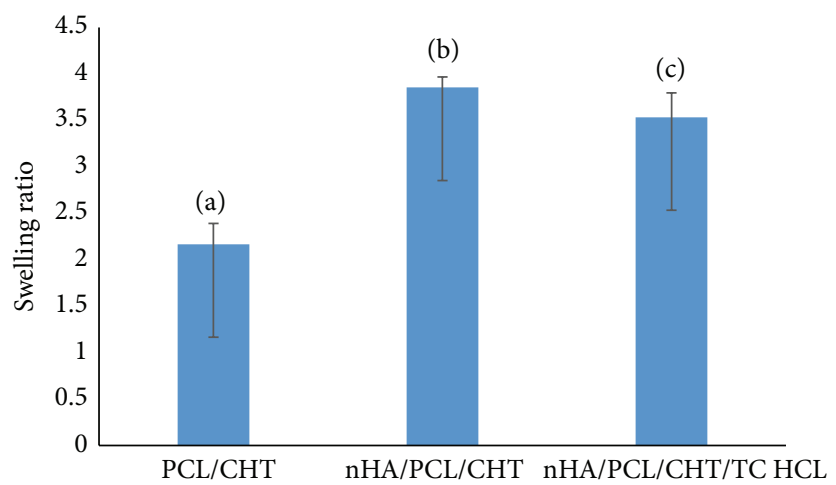

FIGURE 3: Swelling ratio for the three types of scaffolds: (a) PCL/chitosan; (b) NHA/PCL/chitosan; (c) nHA/PCL/chitosan/tetracycline HCL. 


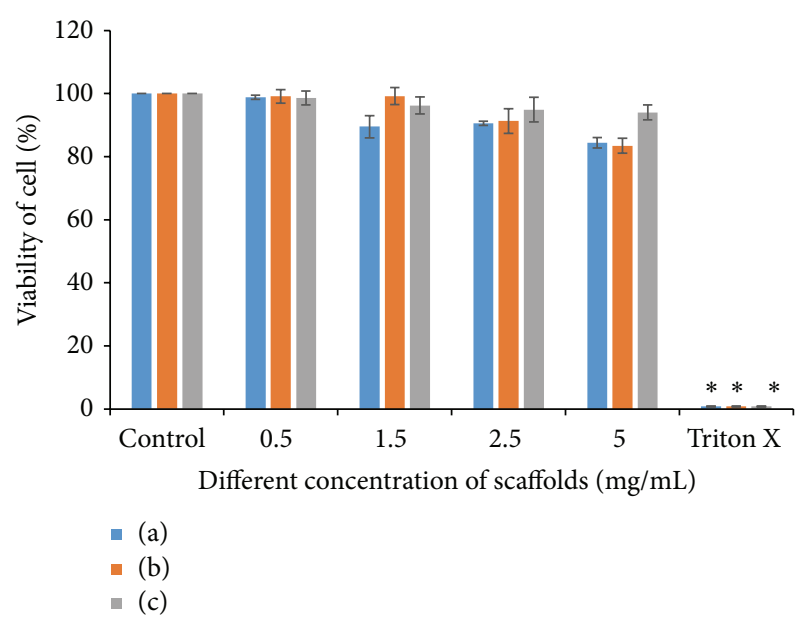

FIgURE 4: Cell viability of seeded HSF 1184 (cell $2 \times 10^{5} / \mathrm{cm}^{2}$ ) using MTT assay. MTT assay was performed after $72 \mathrm{~h}$ treatment of different concentration of scaffolds $0.5,1.5,2.5$, and $5.0 \mathrm{mg} / \mathrm{mL}$ for each sample: (a) PCL/chitosan scaffolds, (b) nHA/PCL/chitosan scaffolds, and (c) nHA/PCL/chitosan/tetracycline $\mathrm{HCl}$ scaffolds and control (cell without treatment). The treatment was carried out with 3 replicates $(n=3)$. The statistical significant analysis paired $t$-test at $P<0.05$ was indicated $(*)$ compared to control cells.

3.4. Cytotoxicity. For applications as implants, it is critical that the scaffolds are biocompatible with mammalian cells. Scaffolds that are toxic or release toxic byproducts or waste will kill the cells and worsen the conditions of the targeted implant area. Therefore, the toxicities of the scaffolds were examined by indirect MTT assays using human skin fibroblasts (HSF 1148) as the model cells. This study used a calorimetric method for measuring the ability of live cells to reduce the tetrazolium salt in the MTT into formazan crystals. Figure 4 shows the MTT assay results after three days of treatment. Among all the treatments with different concentration of conditioned media obtained from the scaffolds, it was observed that there was no significant decrease in cell viability compared to control cells, while the cells treated with Triton-X that acted as positive control showed higher toxicity compared to control cell (without treatment). The viability test was statistically analysed using Student's two-tailed $t$-test; a value of $P<0.05$ was considered statistically significant. These results showed that all of the fabricated scaffolds were nontoxic towards HSF-1184 cells. As the cytotoxicity assay confirmed nontoxicity of scaffolds to HSF-1184 cells via several concentrations, the treatment was carried forward to cell proliferation activities as shown in Figure 5.

3.5. Proliferation Activities. Cell proliferation was performed to evaluate the ability of HSF 1184 cells to grow on the surface of all scaffolds. The proliferation was assessed by measuring the metabolic activity of the cells using MTT assay. Overall analysis is shown in Figure 5 which indicates the proliferation activities of the cells grown on the surface of the PCL/chitosan scaffolds, nHA/PCL/chitosan scaffolds, and

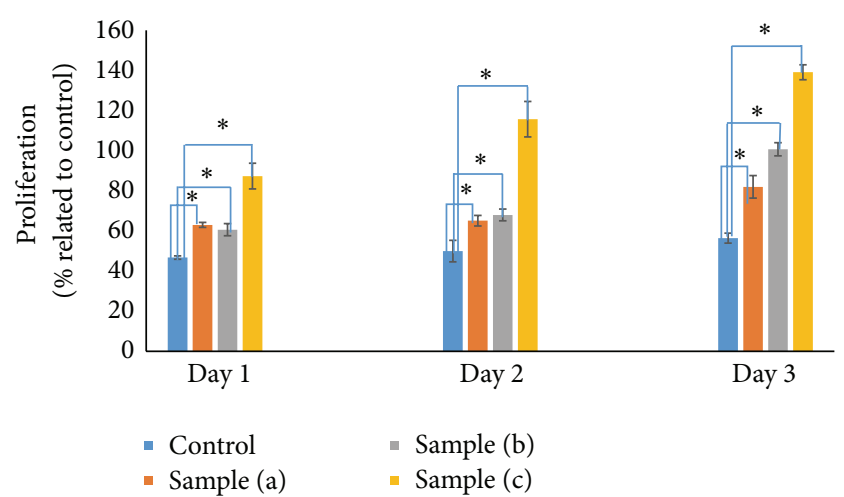

Figure 5: Cell proliferation of seeded HSF 1184, (cell $2 \times 10^{5} / \mathrm{cm}^{2}$ ) by MTT assay. MTT assay was performed after day 1 to day 3 for each sample: (a) PCL/chitosan scaffolds, (b) nHA/PCL/chitosan scaffolds, and (c) nHA/PCL/chitosan/tetracycline $\mathrm{HCl}$ scaffolds. The treatment was carried out with 3 replicates $(n=3)$. The statistical significant analysis paired $t$-test at $P<0.05$ was indicated $(*)$ compared to control cells.

nHA/PCL/chitosan/tetracycline $\mathrm{HCl}$ scaffolds. The cell proliferation significantly increased in all the scaffolds compared to control for day 1 to day 3. Moreover, the HA/ $\mathrm{PCL} /$ chitosan/tetracycline HCL $(139.12 \pm 3.71)$ and nHA/ $\mathrm{PCL} /$ chitosan $(100.73 \pm 3.25)$ scaffolds showed higher proliferation than PCL/chitosan $(81.76 \pm 5.58)$ scaffolds and the control $(56.40 \pm 2.51)$ at day 3 .

This difference may be caused by cells undergoing specific morphological changes to stabilize the cell-material interface involving cell adhesion and spreading. One of the reliable hypotheses is that addition of nHA and tetracycline HCL helped to improve the cell's ability to grow and proliferate much faster on the surface of the scaffolds. Following proliferation, cells undergo filopodial growth, cytoplasmic webbing, flattening of the cell mass, and ruffling of peripheral cytoplasm [17]. These results proved that the cells were successfully attached to the surfaces of the scaffolds and able to proliferate throughout the scaffolds. Cell attachment and proliferation on the surfaces of the scaffolds are shown in Figure 6.

As shown in Figure 7, the micrographs showed cells, spherical or roughly spherical in shape, with smooth rounded surfaces, which indicates two types of physical appearances of cells during proliferation: cells in the advanced stage of adhesion and the early stage of spreading. The filopodia extensions have been reported as being associated with substrate-exploring functions for various cell types, expressing long transient filopodia in their spherical state prior to spreading. However, due to HSF cells interacting and integrating well with the scaffolds, the ends of the dendritic extensions penetrating into the walls of the scaffolds, and the over confluence of the cells, differentiation by SEM is difficult.

3.6. Antibacterial Analysis. Chitosan is widely used as an antimicrobial agent either alone or blended with other natural polymers because it has high biodegradability, is nontoxic, and has antimicrobial properties $[18,19]$. Bacterial 

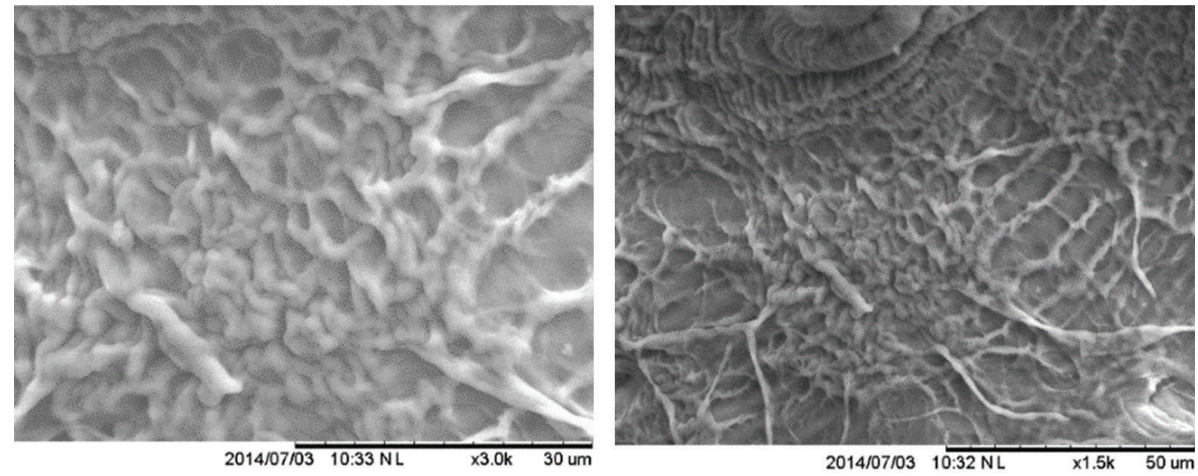

FIGURE 6: Attachment of human skin fibroblasts (HSF 1184) on the surfaces of the scaffolds.

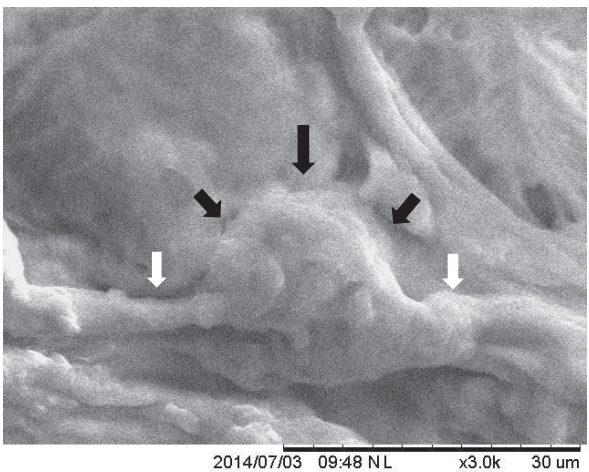

FIGURE 7: SEM micrograph of HSF (1184) cells cultured on the scaffolds for three days shows cells in the advanced stage of adhesion, when cells adhere to the surface with short filopodia (black arrows) extending into long conical protrusions (dendritic extensions, white arrows) that interpenetrate into the scaffolds.

contaminations during operative procedures, such as open procedures, always have contamination risks; however, the presence of biomaterials increases the risk of infection due to their susceptibility to bacterial colonization. In fact, the pores or porous structure of the scaffold is more likely to be a suitable place for bacterial colonization. Antibacterial analysis of the $\mathrm{PCL} /$ chitosan, nHA/PCL/chitosan, and tetracycline $\mathrm{HCL} / \mathrm{nHA} / \mathrm{PCL} /$ chitosan composite scaffolds using $E$. coli (gram-negative bacteria) and Bacillus cereus (grampositive bacteria) has been conducted, and the results are shown in Table 2 and Figure 8.

The results showed a negative result for the PCL/chitosan and nHA/PCL/chitosan scaffolds toward E. coli and Bacillus cereus, even though chitosan has been well studied for its nontoxic, antibacterial, biodegradable, and biocompatible properties [20]. This result showed that blending PCL with chitosan had no antibacterial properties of the chitosan as the content is low. Enhancing the antibacterial properties of the blend, tetracycline HCL incorporated into the scaffold showed good results on gram-positive and gram-negative bacteria. The scaffolds produced using this technique could be used successfully in tissue engineering applications as they
TABLE 2: Antibacterial analysis of the scaffolds with gram-positive and gram-negative bacteria.

\begin{tabular}{|c|c|c|c|c|}
\hline Samples (scaffold) & Bacteria & of in & $\begin{array}{l}\text { esult } \\
\text { mete } \\
\text { on } \mathrm{z}\end{array}$ & $(\mathrm{cm}))$ \\
\hline \multirow{2}{*}{ PCL/chitosan } & E. coli & - & - & - \\
\hline & $\begin{array}{l}\text { Bacillus } \\
\text { cereus }\end{array}$ & - & - & - \\
\hline \multirow[b]{2}{*}{$\mathrm{PCL} /$ chitosan/nHA } & E. coli & - & - & - \\
\hline & $\begin{array}{c}\text { Bacillus } \\
\text { cereus }\end{array}$ & - & - & - \\
\hline \multirow{2}{*}{$\begin{array}{l}\mathrm{PCL} / \text { chitosan/nHA/ } \\
\text { Tetracycline HCL }\end{array}$} & E. coli & 1.7 & 1.9 & 2.0 \\
\hline & $\begin{array}{c}\text { Bacillus } \\
\text { cereus }\end{array}$ & 2.7 & 2.8 & 2.8 \\
\hline
\end{tabular}

exhibit suitable properties such as porous structure, pore sizes, wettability, and nontoxicity [21, 22].

\section{Conclusions}

$\mathrm{PCL} /$ chitosan, nHA/PCL/chitosan, and nHA/PCL/chitosan/ tetracycline HCL scaffolds were successfully fabricated. The scaffolds had suitable pore sizes, which are very important for cell penetration, adhesion, and spreading. The scaffolds were nontoxic when tested on human skin fibroblasts (HSF1184). However, incorporation of nHA after blending chitosan with PCL increased the wettability or hydrophilicity of the scaffolds. Tetracycline HCL drug was incorporated to enhance the antibacterial properties of the scaffolds. The scaffolds were produced with suitable properties for tissue engineering applications.

\section{Conflict of Interests}

The authors declare that there is no conflict of interests regarding the publication of this paper. 


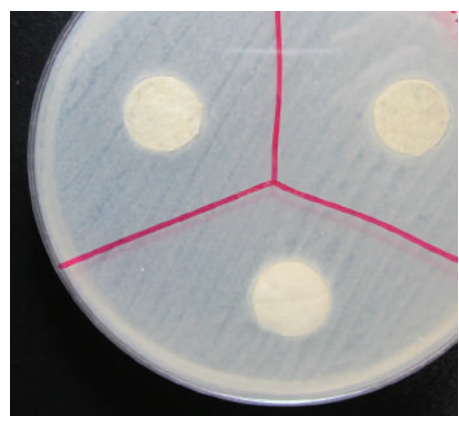

(a)

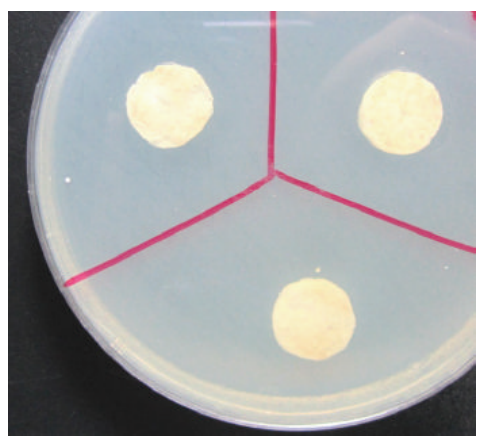

(d)

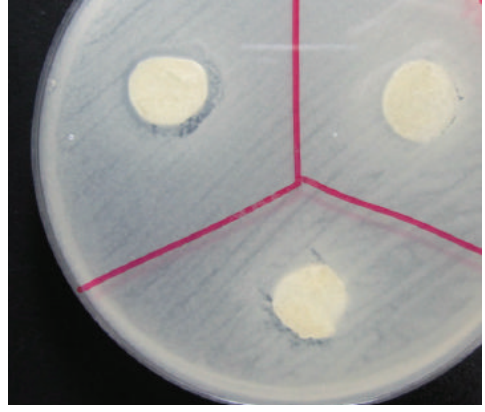

(b)

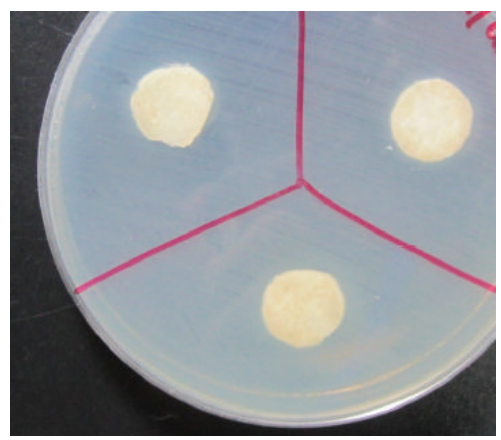

(e)

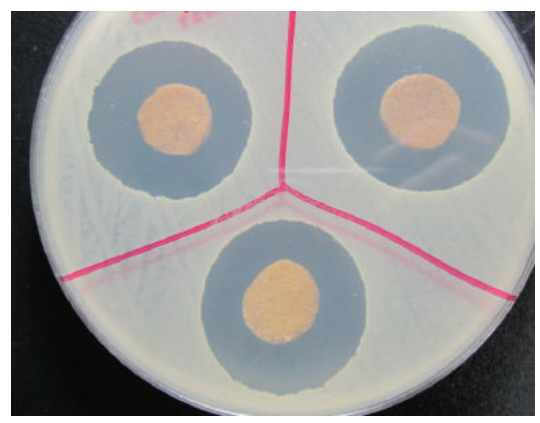

(c)

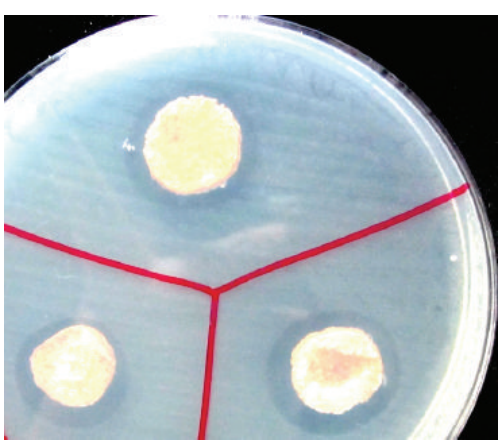

(f)

Figure 8: Antibacterial analysis of the scaffolds: ((a), (d)) PCL/chitosan, ((b), (e)) nHA/PCL/chitosan, and ((c), (f)) nHA/PCL/chitosan/tetracycline HCL on Bacillus cereus (gram-negative) and E. coli (gram-positive) bacteria.

\section{Acknowledgments}

The authors would like to acknowledge the Faculty of Biosciences and Medical Engineering, Universiti Teknologi Malaysia (UTM), for the lab facilities. This work was supported by the following research Grants: FRGS (vot no. 4F507) and GUP Tier 1 (06H84, 05H07). The authors also acknowledge the support provided by MOHE, RMC, and UTM.

\section{References}

[1] M. Biondi, F. Ungaro, F. Quaglia, and P. A. Netti, "Controlled drug delivery in tissue engineering," Advanced Drug Delivery Reviews, vol. 60, no. 2, pp. 229-242, 2008.

[2] S. Saravanan, S. Nethala, S. Pattnaik, A. Tripathi, A. Moorthi, and N. Selvamurugan, "Preparation, characterization and antimicrobial activity of a bio-composite scaffold containing chitosan/nano-hydroxyapatite/nano-silver for bone tissue engineering," International Journal of Biological Macromolecules, vol. 49, no. 2, pp. 188-193, 2011.

[3] M. A. Woodruff and D. W. Hutmacher, "The return of a forgotten polymer-polycaprolactone in the 21st century," Progress in Polymer Science, vol. 35, no. 10, pp. 1217-1256, 2010.

[4] V. K. Mourya and N. N. Inamdar, "Chitosan-modifications and applications: opportunities galore," Reactive and Functional Polymers, vol. 68, no. 6, pp. 1013-1051, 2008.

[5] S. C. Neves, L. S. M. Teixeira, L. Moroni et al., "Chitosan/poly( $\varepsilon$ caprolactone) blend scaffolds for cartilage repair," Biomaterials, vol. 32, no. 4, pp. 1068-1079, 2011.
[6] A. Rezaei and M. R. Mohammadi, "In vitro study of hydroxyapatite/polycaprolactone (HA/PCL) nanocomposite synthesized by an in situ sol-gel process," Materials Science and Engineering C, vol. 33, no. 1, pp. 390-396, 2013.

[7] A. N. Sapadin and R. Fleischmajer, "Tetracyclines: nonantibiotic properties and their clinical implications," Journal of the American Academy of Dermatology, vol. 54, no. 2, pp. 258-265, 2006.

[8] M. E. Parolo, M. J. Avena, G. Pettinari, I. Zajonkovsky, J. M. Valles, and M. T. Baschini, "Antimicrobial properties of tetracycline and minocycline-montmorillonites," Applied Clay Science, vol. 49, no. 3, pp. 194-199, 2010.

[9] J. B. Payne and L. M. Golub, "Using tetracyclines to treat osteoporotic/osteopenic bone loss: from the basic science laboratory to the clinic," Pharmacological Research, vol. 63, no. 2, pp. 121129, 2011.

[10] W. Cao and L. L. Hench, "Bioactive materials," Ceramics International, vol. 22, no. 6, pp. 493-507, 1996.

[11] F. Franks, "Freeze-drying of bioproducts: putting principles into practice," European Journal of Pharmaceutics and Biopharmaceutics, vol. 45, no. 3, pp. 221-229, 1998.

[12] Y. Wan, H. Wu, X. Cao, and S. Dalai, "Compressive mechanical properties and biodegradability of porous poly(caprolactone)/ chitosan scaffolds," Polymer Degradation and Stability, vol. 93, no. 10, pp. 1736-1741, 2008.

[13] V. N. Malheiro, S. G. Caridade, N. M. Alves, and J. F. Mano, "New poly( $\varepsilon$-caprolactone)/chitosan blend fibers for tissue engineering applications," Acta Biomaterialia, vol. 6, no. 2, pp. 418-428, 2010.

[14] B. Duan and M. Wang, "Encapsulation and release of biomolecules from $\mathrm{Ca}-\mathrm{P} / \mathrm{PHBV}$ nanocomposite microspheres and 
three-dimensional scaffolds fabricated by selective laser sintering," Polymer Degradation and Stability, vol. 95, no. 9, pp. 16551664, 2010.

[15] W. Y. Zhou, M. Wang, W. L. Cheung, B. C. Guo, and D. M. Jia, "Synthesis of carbonated hydroxyapatite nanospheres through nanoemulsion," Journal of Materials Science: Materials in Medicine, vol. 19, no. 1, pp. 103-110, 2008.

[16] I. Armentano, M. Dottori, E. Fortunati, S. Mattioli, and J. M. Kenny, "Biodegradable polymer matrix nanocomposites for tissue engineering: a review," Polymer Degradation and Stability, vol. 95, no. 11, pp. 2126-2146, 2010.

[17] R. Machado, A. da Costa, V. Sencadas et al., "Electrospun silkelastin-like fibre mats for tissue engineering applications," Biomedical Materials, vol. 8, no. 6, Article ID 065009, 2013.

[18] M. Kong, X. G. Chen, K. Xing, and H. J. Park, "Antimicrobial properties of chitosan and mode of action: a state of the art review," International Journal of Food Microbiology, vol. 144, no. 1, pp. 51-63, 2010.

[19] R. Jayakumar, M. Prabaharan, S. V. Nair, and H. Tamura, "Novel chitin and chitosan nanofibers in biomedical applications," Biotechnology Advances, vol. 28, no. 1, pp. 142-150, 2010.

[20] Z. R. Domingues, M. E. Cortés, T. A. Gomes et al., "Bioactive glass as a drug delivery system of tetracycline and tetracycline associated with $\beta$-cyclodextrin," Biomaterials, vol. 25, no. 2, pp. 327-333, 2004.

[21] T. Sun, T. H. Khan, and N. Sultana, "Fabrication and in vitro evaluation of nanosized hydroxyapatite/chitosan- based tissue engineering scaffolds," Journal of Nanomaterials, vol. 2014, Article ID 194680, 8 pages, 2014.

[22] N. Sultana and T. H. Khan, "Factorial study of compressive mechanical properties and primary in vitro osteoblast response of PHBV/PLLA scaffolds," Journal of Nanomaterials, vol. 2012, Article ID 656914, 8 pages, 2012. 

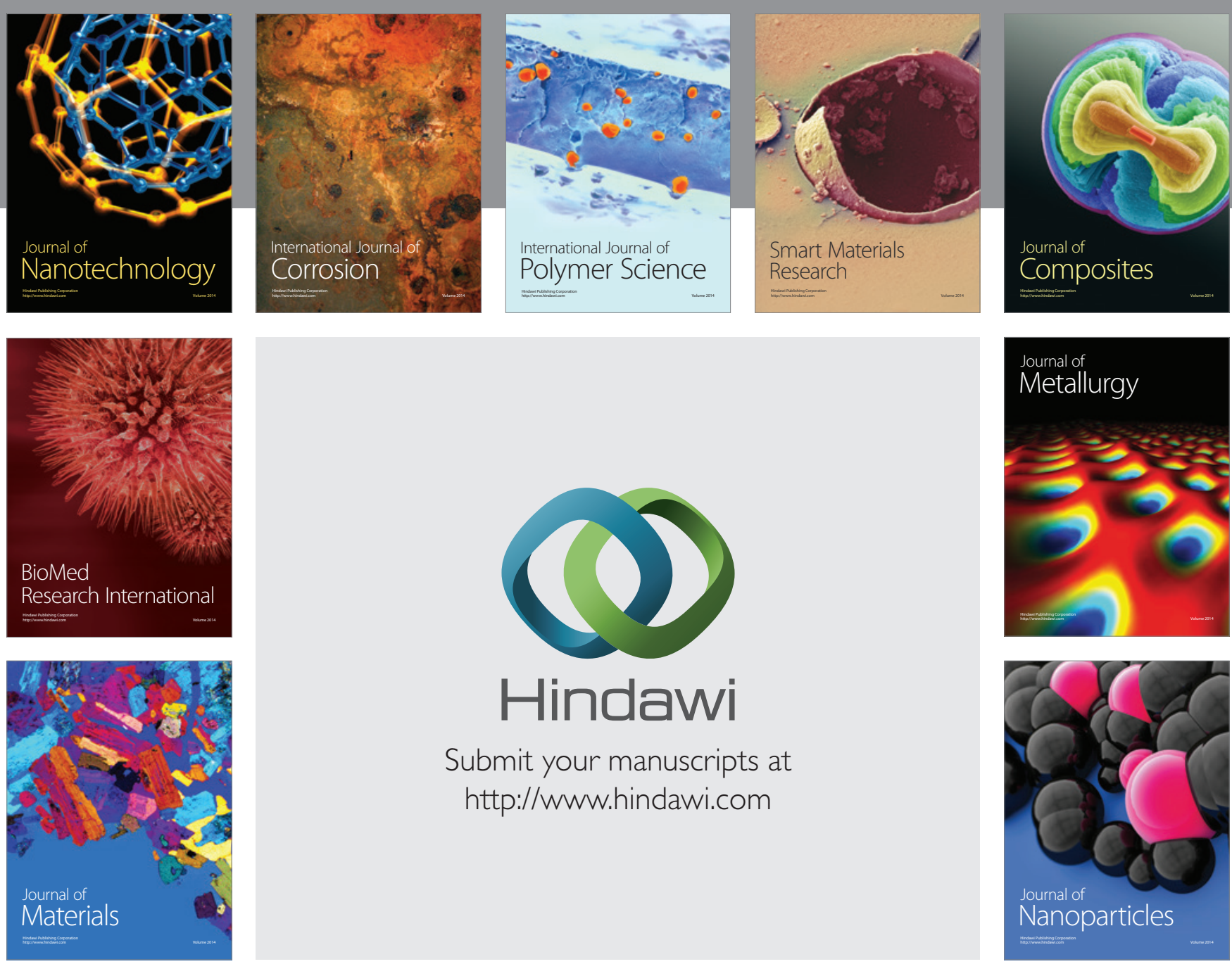

Submit your manuscripts at http://www.hindawi.com
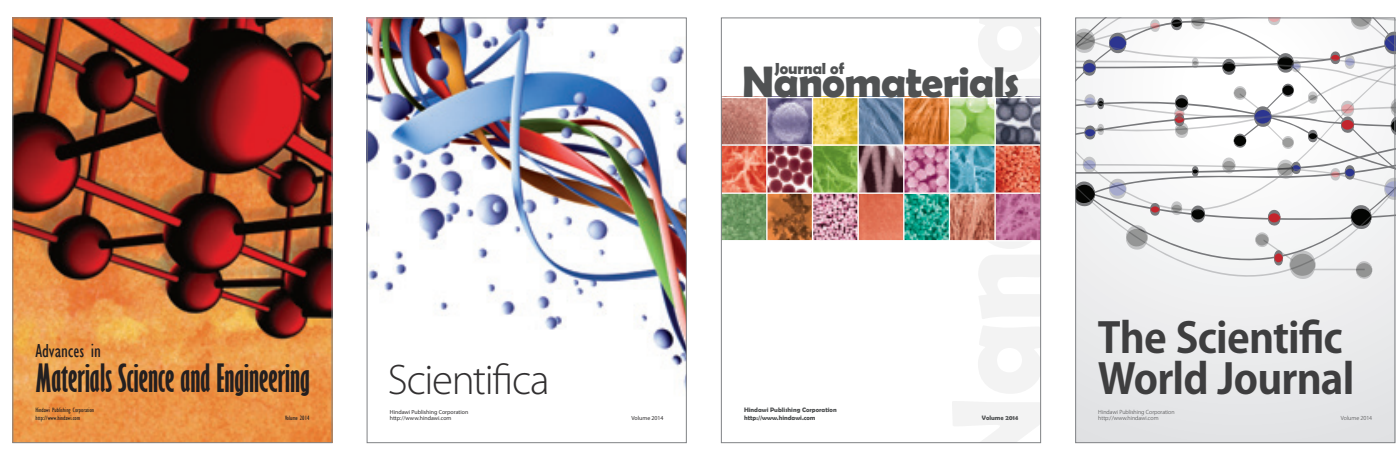

\section{The Scientific World Journal}
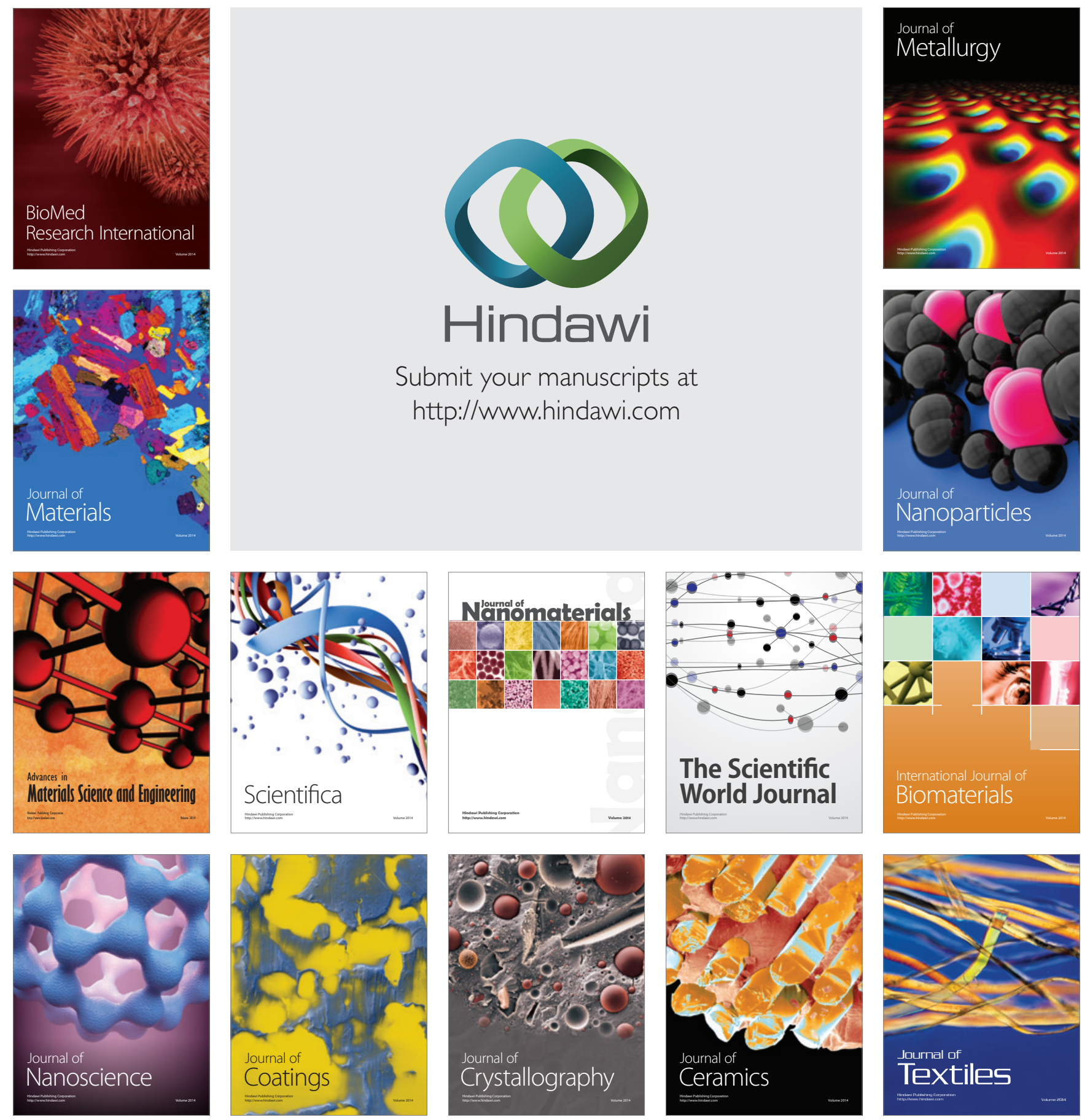